\title{
Abiraterone: a review of its pharmacokinetic, pharmacodynamic profile and clinical efficacy
}

\begin{abstract}
Prostate cancer is a common cancer and it causes significant morbidity and mortality in elderly males. Management for metastatic castration resistant prostate cancer has improved tremendously over the last decade with newer agents improving overall survival and quality of life of patients. Until recently, docetaxel was the only agent to show an improvement in overall survival in patients with metastatic castration-resistant prostate cancer (mCRPC). Of late, many new agents with different mode of action and therapeutic targets have improved overall survival and several new drugs (Cabazitaxel, Sipuleucel-T, abiraterone acetate, Enzalutamide and radium-233) were FDA approved for the treatment of patients with mCRPC. This article reviews current concepts and emerging treatment options in mCRPC followed by phase III studies of abiraterone and newer emerging role of abiraterone like the effect of low dose abiraterone acetate with food and the role of abiraterone as neoadjuvant therapy for localized high risk prostate cancer (LHRPC). The review will also discuss the role of abiraterone in skeletal related events as they are a major cause of morbidity and mortality in patients with metastatic castration-resistant prostate cancer.
\end{abstract}

Volume 3 Issue $3-2016$

\author{
Kapil Dev Mehta, Hanmant Barkate \\ Intas pharmaceuticals limited, India
}

Correspondence: Kapil Dev Mehta, Medical Advisor (Urology), Intas pharmaceuticals limited, 7th floor, premier house -I,Ahmedabad, Gujrat, 380054, India, Tel 7874856742, Email kapildev_mehta@intaspharma.com

Received: March 28, 2016 | Published: May 10, 2016
Abbreviations: mCRPC, metastatic castration-resistant prostate cancer; LHRPC, localized high risk prostate cancer; CRPC, castration-resistant prostate cancer; ACTH, adrenocorticotropic hormone; PSA, prostate-specific antigen; FDA, food and drug administration; BTT, bone-targeted therapies; AA, abiraterone acetate; $\mathrm{OD}$, once daily; PSA-RR, prostate-specific antigen response rate; OS, overall survival; bPFS, biochemical progression-free survival; CRPC, castration-resistant prostate cancer.

\section{Introduction}

Prostatecancerisa commoncanceranditcauses significantmorbidity and mortality in elderly males. It affects approximately 1out 6 men in their lifetime. ${ }^{1}$ Prostate cancer is a slow growing, testosterone dependent cancer and most people present with a localized indolent disease. $^{2}$ In the initial stages it can be efficiently managed with hormonal therapy. However, as the duration increases the cancer becomes resistant to conventional therapy and is termed as castrationresistant prostate cancer (CRPC). Castration-resistant prostate cancer (CRPC) can be defined in terms of biochemical progression (elevated PSA only), radiographic progression (metastatic disease [mCRPC]), or symptomatic progression. ${ }^{3}$ Before 2004, there was no FDA approved agent for the management of metastatic castration-resistant prostate cancer (mCRPC) and patients were given mainly palliative care. In 2004, a study by Tannock et al., ${ }^{4}$ demonstrated that docetaxel can improve survival of patients with mCRPC. In the last 11 years, the scenario has changed dramatically. Today there are many US FDA approved drugs (Cabazitaxel, Sipuleucel-T, Denosumab, Abiraterone acetate, enzalutamide and radium 233) for the management of metastatic castration-resistant prostate cancer (mCRPC). ${ }^{5}$ While none of these treatments are curative, these new drugs can improve overall survival and slow the progression of disease. This review article will give brief description of current and emerging treatment options with focus on abiraterone.

\section{Overview of the recently approved treatment options}

The armamentarium of drug therapies in prostate cancer (specially mCRPC) has vastly improved upon the use of docetaxel since its approval in 2004. Today numerous options are available for the treatment of mCRPC like new hormonal agents, immunotherapy, second-line chemotherapy as well as radiopharmaceuticals see Table 1. The sequencing of drugs mainly relies on symptoms of disease, patient general condition, and whether symptoms are present or not. ${ }^{6}$ Initial options for mCRPC include docetaxel, Sipuleucel-T, abiraterone and radium-223. Sipuleucel-T, generally works well for patients with asymptomatic or minimally symptomatic mCRPC with no visceral metastases while treatment with cabazitaxel generally works well for patients who progressed despite docetaxel-based chemotherapy. Radium-223 is used predominantly for patients with metastatic bone disease from mCRPC with good performance status and no prior docetaxel chemotherapy and without known visceral disease. All these agents have improved the survival of patients with mCRPC but patient unfortunately becomes resistant to the initial therapy. Patients who have progressed after docetaxel based chemotherapy the following drugs can be used -cabazitaxel, abiraterone acetate, enzalutamide.

\section{Sequencing of drugs in mCRPC}

In the last 5 years a lot of new drugs have arrived on the horizon for the treatment of mCRPC. This has led to a debate on the correct sequencing of these drugs. According to 2014 AUA guidelines ${ }^{7}$ for $\mathrm{mCRPC}$ the following drugs can be offered in the below mentioned patient categories.

I. In asymptomatic or minimally symptomatic, mCRPC without prior docetaxel chemotherapy: Abiraterone +prednisone, enzalutamide, docetaxel chemo therapy and Sipuleucel-T immunotherapy are acceptable options.

II. In symptomatic, mCRPC with good performance status and no prior docetaxel chemotherapy: Abiraterone +prednisone, enzalutamide, docetaxel chemotherapy can be considered.

III. In symptomatic, mCRPC with poor performance status and no prior docetaxel chemotherapy: abiraterone +prednisone or enzalutamide may be offered.

IV. In symptomatic, mCRPC with good performance status and prior 
docetaxel chemotherapy: abiraterone + prednisone, cabazitaxel or enzalutamide may be offered.

V. In symptomatic, mCRPC with poor performance status and prior docetaxel chemotherapy: abiraterone +prednisone, enzalutamide can be offered.

\section{Abiraterone mechanism of action}

Abiraterone acetate is an oral prodrug and when ingested it is converted to its active metabolite, abiraterone in liver. Both abiraterone and abiraterone acetate are selective irreversible inhibitors of CYP1. As compared to ketoconazole, only one tenth of abiraterone is required to inhibit CYP17 activity by $50 \%$ in human microsomes. ${ }^{8}$

\section{Pharmacodynamic properties}

The pharmacodynamics of abiraterone acetate are well known and are discussed briefly here; Abiraterone, selectively inhibits the enzyme CYP17 (17 $\alpha$ - Hydroxylase and C17,20 -lyase) [9]. These enzymes are required for the synthesis of testosterone in the body. As a consequence of $17 \alpha$-Hydroxylase inhibition there is reduction of cortisol levels and elevation of adrenocorticotropic hormone (ACTH) levels. After abiraterone therapy there is rise of deoxycorticosterone and corticosterone levels, resulting in secondary mineralocorticoid excess characterized by hypokalaemia, hypertension and fluid retention or oedema. To prevent the imbalance between glucocorticoid and mineralocorticoid activity, abiraterone must be taken with prednisone.

Table I Newer agents for Metastatic castration- resistant prostate cancer

\begin{tabular}{|c|c|c|c|c|}
\hline Group & Mechanism of action & $\begin{array}{l}\text { Population studied (trial } \\
\text { name) }\end{array}$ & Intervention & $\begin{array}{l}\text { Primary end point } \\
\text { outcomes }\end{array}$ \\
\hline \multirow[t]{2}{*}{$\begin{array}{l}\text { Abiraterone } \\
+ \text { Prednisone }\end{array}$} & $\begin{array}{l}\text { Selective and irreversible inhibitor } \\
\text { of CYPI } 7\end{array}$ & $\begin{array}{l}\text { mCRPC previously treated with } \\
\text { a docetaxel-containing regimen } \\
(\text { COU-AA-30I })^{11,12}\end{array}$ & $\begin{array}{l}\text { Arm I:Abiraterone I,000 mg } \\
\text { PO daily+ Prednisone } 5 \mathrm{mg} \\
\text { PO BID } \\
\text { Arm 2: Placebo+ Prednisone } 5 \\
\text { mg PO BID }\end{array}$ & $\begin{array}{l}\text { OS benefit: } 4.6 \text { months } \\
\text { (I } 5.8 \text { versus } 11.2 \\
\text { months) }\end{array}$ \\
\hline & & $\begin{array}{l}\text { mCRPC not pretreated } \\
\text { with chemotherapy (COU- } \\
\text { AA-302) }\end{array}$ & $\begin{array}{l}\text { Arm I:Abiraterone } 1,000 \mathrm{mg} \\
\text { PO daily + Prednisone } 5 \mathrm{mg} \\
\text { PO BID } \\
\text { Arm 2: Placebo + Prednisone } 5 \\
\text { mg PO BID }\end{array}$ & $\begin{array}{l}\text { rPFS benefit: } 8.3 \text { months } \\
\text { (I } 6.5 \text { versus } 8.2 \text { months) } \\
\text { OS increased ( } 35.1 \\
\text { versus } 30.1 \text { months)** }\end{array}$ \\
\hline
\end{tabular}

A pure AR signaling inhibitor with no agonistic properties. Also prevents the translocation of the AR from cytoplasm to nucleus, DNA binding, and co-activator mobilization

mCRPC previously treated withArm I: Enzalutamide $160 \mathrm{mg}$ a docetaxel-containing regimen $\mathrm{PO}$ daily $(\mathrm{AFFIRM})^{8} \quad$ Arm 2: Placebo OS benefit: 4.8 months (I8.4 versus 13.6 months)
mCRPC with symptomatic Arm I: One injection of

Radium 223

An alpha emitter, selectively targets one metastases and no known bone metastases with alpha particlesvisceral metastatic disease.

(ALSYMPCA)

$\mathrm{kBq} / \mathrm{kg}$ )

Arm 2: Placebo
An autologous cellular immunotherapy designed to induce Asymptomatic or minimally an immune response targeted symptomatic patients with against PAP, an antigen expressed in mCRPC (IMPACT) $)^{10}$ most prostate cancers

Sipuleucel-T

Docetaxel + Prednisone

Microtubule inhibitor

mCRPC $(\operatorname{TAX} 327)^{4}$
Arm I: Sipuleucel-T infusions Arm 2: Placebo

Arm I: Docetaxel 75 mg/ $\mathrm{m}^{2}+$ Prednisone $5 \mathrm{mg}$ PO BID Arm 2: Mitoxantrone $12 \mathrm{mg} /$ $\mathrm{m}^{2}+$ Prednisone $5 \mathrm{mg}$ PO BID
OS benefit: 3.6 months (I4.9 versus II.3 months)

OS benefits: 4.1 months ( 25.8 versus 21.7 months

OS benefit: 2.4 months (I8.9 versus I6.5 months)

OS benefit: 2.4 months (I5.I versus 12.7 months)
Semisynthetic taxane inhibiting microtubule depolymerization and celldivision by binding to tubulin
mCRPC previously treatedwith a docetaxel-containing regimen (TROPIC)
Arm I: Cabazitaxel $25 \mathrm{mg} /$ $\mathrm{m}^{2}+$ Prednisone $5 \mathrm{mg}$ PO BID

Arm 2: Mitoxantrone 12 mg/ $\mathrm{m}^{2}+$ Prednisone $5 \mathrm{mg}$ PO BID

Abbreviations: AFFIRM, a study evaluating the efficacy and safety of the investigational drug mdv3 I00;ALSYMPCA, alpharadin in symptomatic prostate cancer patients; AR, Androgen Receptor; BID, twice daily; CYPI7, microsomal enzyme cytochrome p450 isoform- I7; FDA, US food and drug administration; IMPACT, immunotherapy for prostate adenocarcinoma treatment; IV, intravenous; mCRPC, metastatic castration-resistant prostate cancer; OS, overall survival; PO, orally; rPFS, radiographic progression-free survival; PAP, prostatic acid phosphatase; PSA, prostate specific antigen; PFS, progression free survival; q3, every three. 


\section{Pharmacokinetic properties}

The pharmacokinetics of abiraterone acetate is well known and is discussed briefly in (Table 2). ${ }^{9}$ Special Populations: Mild (Child-Pugh class A) hepatic impairment had minimal effects on the pharmacokinetics of abiraterone, thus, dosage adjustment is not required in these patients. ${ }^{9}$ Mean abiraterone $\mathrm{C}_{\max }, \mathrm{AUC}_{\text {last }}$ and $\mathrm{AUC}_{\infty}$ values were elevated approximately 3.5-, 4.8- and 4.7-fold in patients with moderate (Child-Pugh class $\mathrm{B} ; \mathrm{n}=8$ ) hepatic impairment versus subjects with normal hepatic function $(n=8)$; the mean halflife of abiraterone was prolonged to approximately $19 \mathrm{~h}$ in patients with moderate hepatic impairment. In patients with moderate hepatic impairment maximum approved dosage is $250 \mathrm{mg}$ once daily. ${ }^{9}$ There is no supporting data on severe hepatic impairment; therefore, abiraterone acetate must not be used in this patient population is contraindicated. The systemic exposure (based on geometric mean $\mathrm{C}_{\max }, \mathrm{AUC}_{\text {last }}$ and $\mathrm{AUC}_{\infty}$ values) of abiraterone was not elevated with a single dose of abiraterone acetate $1,000 \mathrm{mg}$ in patients with end-stage renal disease requiring haemodialysis. Hence, in patients with renal impairment there is no need to adjust the dose of abiraterone acetate. ${ }^{9}$

Table 2 Pharmacokinetics of Abiraterone acetate

\begin{tabular}{ll}
\hline Parameter & Value \\
\hline$T_{\text {max }}$ & 2 hours \\
$\begin{array}{l}\text { Steady-state values (mean } \pm S D) \\
\text { of Cmax }\end{array}$ & $226 \pm 178 \mathrm{ng} / \mathrm{mL}$ \\
AUC & $993 \pm 639 \mathrm{ng} \cdot \mathrm{hr} / \mathrm{mL}$ \\
Protein Binding & $>99 \%$ \\
$\begin{array}{l}\text { Volume of distribution } \\
\text { (mean } \pm S D \text { ) }\end{array}$ & $19,669 \pm 13,358$ \\
Mean terminal half-life & $12 \pm 5$ hours \\
Excretion & $88 \%$ in feces and \\
\end{tabular}

\section{Phase III clinical studies of abiraterone}

Approval of abiraterone acetate was granted on the basis of a Phase III study in which patients with metastatic CRPC who had received prior docetaxel chemotherapy were included. In this study ${ }^{10,11}$ a total of 1195 patients were randomized 2:1 to receive either abiraterone acetate orally at a dose of $1,000 \mathrm{mg}$ once daily in combination with prednisone $5 \mathrm{mg}$ orally twice daily $(\mathrm{N}=797)$ or placebo once daily plus prednisone $5 \mathrm{mg}$ orally twice daily $(\mathrm{N}=398)$. The primary end point was overall survival. The secondary end points included time to prostate-specific antigen (PSA) progression (elevation in the PSA level according to prespecified criteria), progression-free survival according to radiologic findings based on prespecified criteria, and the PSA response rate Treatment was continued until clinical or radiographic evidence of progression. Results of primary and secondary endpoints are provided in Table 3.

The primary endpoint was met with significant overall survival (OS) benefit for men receiving abiraterone (14.8 months versus 10.9 months for placebo; hazard ratio $[\mathrm{HR}] 0.646 ; P<0.0001)$ at a median follow-up of 12.8 months. After final analysis a median OS was 15.8 months for abiraterone versus 11.2 months for prednisone (HR $0.74 ; P<0.0001$ ), extending the OS benefit to 4.6 months. In the trial COU-AA-301, abiraterone was well tolerated in the trial and the most common adverse reactions (more than 5 percent of patients) were joint swelling or discomfort, hypokalemia, edema, muscle discomfort, hot flush, diarrhea, urinary tract infection, cough, hypertension, arrhythmia, urinary frequency, Nocturia, dyspepsia, and upper respiratory tract. In conclusion, this study (COUAA-301) demonstrated that abiraterone acetate prolongs survival in patients with metastatic castration-resistant prostate cancer who had progressed after docetaxel-based chemotherapy, with a low frequency of additional treatment-related toxic effects.

Table 3 Results of primary and secondary endpoints of trial COU-AA-30 I

\begin{tabular}{|c|c|c|c|}
\hline & $\begin{array}{l}\text { Abiraterone } \\
\text { acetate }\end{array}$ & placebo & $P$ value \\
\hline $\begin{array}{l}\text { Primary Endpoint } \\
\text { Overall survival (OS) }\end{array}$ & I5.8 months & II.2 months & $P<0.0001$ \\
\hline $\begin{array}{l}\text { Secondary Endpoi } \\
\text { Time to PSA progres }\end{array}$ & n 10.2 months & 6.6 months & $p<0.001$ \\
\hline PFS & 5.6 months & 3.6 months & $p<0.001$ \\
\hline PSA response rate & $29 \%$ & $6 \%$ & $p<0.001$ \\
\hline
\end{tabular}

Approved for use with prednisone for metastatic castrationresistant prostate cancer before chemotherapy. On December 10, 2012, abiraterone acetate was approved by the Food and Drug Administration (FDA) for use with prednisone for metastatic castration-resistant prostate cancer before chemotherapy. This approval was based on study COU-AA-302 $2^{12,13}$ which was a Phase 3 multicenter, randomized, double-blind, placebo-controlled study conducted at 151 sites in 12 countries; USA, Europe, Australia, Canada. Patients $(\mathrm{N}=1088)$ were randomized 1:1 to receive abiraterone acetate AA (1g) + Prednisone (5mg po BID) vs Prednisone. Patients randomized to either arm were to continue treatment until disease progression (defined as a $25 \%$ increase in PSA over the patient's baseline/nadir together with protocol-defined radiographic progression and symptomatic or clinical progression), initiation of new treatment, unacceptable toxicity or withdrawal. The primary end points were radiographic progressionfree survival and OS. Results of final analysis are mentioned in Table 4.

Table 4 Results Overall Survival and Radiographic Progression-free Survival of Study COU-AA-302

\begin{tabular}{|c|c|c|}
\hline Survival analysis & $\begin{array}{l}\text { Abiraterone } \\
(\mathrm{N}=546)\end{array}$ & Placebo $(\mathrm{N}=542)$ \\
\hline Deaths (\%) & $354(65 \%)$ & $387(71 \%)$ \\
\hline $\begin{array}{l}\text { Median survival } \\
\text { (months) }(95 \% \mathrm{Cl})\end{array}$ & $34.7(32.7,36.8)$ & $30.3(28.7,33.3)$ \\
\hline $\mathrm{p}$-value I & $<0.0033$ & \\
\hline Hazard ratio $(95 \% \mathrm{Cl})^{2}$ & $0.81(0.70,0.93)$ & \\
\hline \multicolumn{3}{|c|}{ Radiographic progression-free survival } \\
\hline Progression or Death & $150(28 \%)$ & $25 I(46 \%)$ \\
\hline $\begin{array}{l}\text { Median rPFS (months) } \\
(95 \% \mathrm{Cl})\end{array}$ & NR $(1 \mathrm{I} .66, \mathrm{NR})$ & $8.28(8.12,8.54$ \\
\hline p-valuel & $<0.0001$ & \\
\hline Hazard ratio $(95 \% \mathrm{Cl})^{2}$ & $0.425(0.347,0.522)$ & \\
\hline
\end{tabular}

' $\mathrm{P}$-value is derived from a log-rank test stratified by ECOG performance status score ( 0 vs. I).

${ }^{2}$ Hazard Ratio is derived from a stratified proportional hazards model. Hazard ratio $<$ f favors abiraterone. 


\section{Abiraterone effectiveness: before and after chemotherapy}

In one meta-analysis ${ }^{14}$ the efficacy and toxicity of abiraterone treatment in patients with metastatic castration-resistant prostate cancer, before and after chemotherapy was evaluated. 7 RCTs were identified, out of which 5 were excluded because of concomitant medications. Overall, two phase III RCTs were included in the final analysis. The two trials included were COU-AA-301 trial $(n=546)$, COU-AA-302 trial $(n=797)$. The results of the study showed that prior chemotherapy reduces the effect of abiraterone acetate on radiographic-progression-free survival $(P=0.04)$, objective response rate $(P<0.001)$, and PSA response rate $(P<0.001)$. On the other hand prior chemotherapy had no significant effect on overall survival $(P=0.92)$ and prostate-specific antigen (PSA) progression-free survival $(P=0.13)$.The tolerability profile of abiraterone was also favourable for pre chemotherapy setting. The incidence of fluid retention $(\mathrm{P}<0.001)$ and edema $(P<0.001)$ and hypokalemia $(P<0.001)$ was lower and a higher incidence of hypertension was in the pre-chemotherapy setting compared to the post-chemotherapy setting. The greatest clinical benefit to the patient will be seen with early initiation of abiraterone prior to chemotherapy.

\section{Role of abiraterone in skeletal metastasis in patients with castration-resistant prostate cancer}

Skeletal-related events (SREs) are a major cause of morbidity and mortality in patient's metastatic castration-resistant prostate cancer ${ }^{15,16}$ (mCRPC). In the trial COU-AA-301, occurrence of new SREs was $29 \%$ with AA and $33 \%$ with placebo; time to first SRE was significantly longer with $\mathrm{AA}^{10,11}$ (median 25.0 vs. 20.3 months HR $0.615 ; \mathrm{p}=0.0001)$. In terms of pain relief AA produced significantly more $(45.0 \%$ vs. $28.8 \%$; $p=0.0005)$ and faster relief of pain intensity ${ }^{17}$ (median time to palliation 5.6 vs. 13.7 months; $\mathrm{p}=0.0018$ ).

In the trial COU-AA-302 $2^{12,13}$ treatment with $\mathrm{AA}$ demonstrated a significant improvement in time to opiate use (median NR vs. 23.7 months; $\mathrm{p}=0.001$ ), in time to increase in pain (median 26.7 vs. 18.4 months, $\mathrm{p}=0.049$ ), and in time to progression of pain interference (median 10.3 vs. 7.4 months; $p=0.005$ ). For trial COU-AA-302 there is no data available on the occurrence of SREs. In one post hoc analysis ${ }^{18}$ the impact of Abiraterone Acetate was evaluated as bone-targeted therapies (BTT) in chemotherapy-naïve metastatic castration-resistant prostate cancer patients. AA and prednisone was found superior to prednisone alone in terms of improving clinical outcomes without BTT use. Concomitant BTT significantly prolonged the time to opiate use for cancer-related pain (HR 0.80; $\mathrm{p}=0.036$ ), time to performance status deterioration (HR $0.75 ; \mathrm{p}<0.001)$ and significantly improved OS (HR 0.75; $\mathrm{p}=0.01$ ). The result of this post hoc analysis showed that when abiraterone acetate and prednisone are used in combination with bone-targeted therapy they prolong the overall survival in comparison to prednisone monotherapy in patients with mCRPC. In a retrospective analysis ${ }^{19}$ of the Italian Compassionate Use Named Patient Programme. Study of $123 \mathrm{mCRPC}$ patients treated with AA, $29 \%$ reported an improvement during treatment, $32 \%$ no change and $28 \%$ a worsening.

\section{Low dose abiraterone acetate with food}

As per the prescribing information of AA, it should be taken empty stomach. When taken with food the plasma levels of abiraterone, $\mathrm{C}_{\max }$ was approximately 7 times higher, as compared to low fat diet. ${ }^{20} \mathrm{~A}$ pharmacokinetic study on AA demonstrated that the plasma concentration after 250-mg-fed, 500-mg-fed and 1000-mgfasting doses were not significantly different (421, 676 and 510 $\mathrm{nM} / \mathrm{L}$, respectively). ${ }^{21}$ In one clinical trial ${ }^{22}$ the pharmacokinetics of abiraterone acetate were compared after low-fat or high-fat meals in metastatic castration-resistant prostate cancer (mCRPC) patients. In mCRPC patients, abiraterone AUC was 2-fold higher with a highfat meal and similar with a low-fat meal versus modified fasting state. In one retrospective study ${ }^{23}$ the effect of low dose abiraterone acetate (AA) in metastatic castration-resistant was evaluated. 21 (5 at a dose of $250 \mathrm{mg}$ once daily (OD), 13 at a dose of $500 \mathrm{mg}$ OD and three patients at a dose of $250 \mathrm{mg}$ that was later increased to $500 \mathrm{mg}$ OD) men out of 111 received low dose and were evaluated for prostatespecific antigen response rate (PSA-RR), biochemical progressionfree survival (bPFS), treatment duration and overall survival (OS). The main reason for receiving low dose was financial limitations. PSA-RR was $43 \%$ versus $32 \%,(P=0.37)$ and median OS 18.7 versus 16.6 months $(P=0.25)$ in the full and low-dose cohorts respectively this study concluded that outcomes were similar in the in the full and low-dose groups.

One Italian study ${ }^{24}$ evaluated the effectiveness and safety of low dose AA in the treatment of elderly patients between 85 and 93 years of age with castration-resistant prostate cancer (CRPC). In this study, 750 $\mathrm{mg}$ of abiraterone acetate was administered orally with concomitant oral prednisone, $5 \mathrm{mg}$ daily. 26 patients (range, 85 to 93 years) were recruited and PSA response, median time to PSA progression and median overall survival was examined. A PSA response was observed in $18 / 26$ patients (69 percent), median time to PSA progression was 6.4 months and median overall survival was 14.3 months. The authors concluded that low dose of AA $(750 \mathrm{mg})$ and prednisone $5 \mathrm{mg}$ OD is beneficial and well tolerated in this group of elderly patients.

\section{Abiraterone as neoadjuvant therapy for localized high risk prostate cancer (LHRPC)}

The presentation of prostate cancer patients has changed drastically over the last few decades. Unlike today, lot of prostate cancer patients were presenting with metastatic disease. ${ }^{25}$ After the appraisal of prostate specific antigen (PSA) screening, most men are now diagnosed with localized disease. ${ }^{26}$ In localized but high-risk prostate cancer, prostatectomy provides only modest benefit. The size of tumour can be reduced by neoadjuvant therapy and this will help in better surgical resection. ${ }^{27}$ In the past results with neoadjuvant therapy has been disappointing for the management of localized prostate cancer. A possible explanation can be incomplete suppression of tissue androgens. Abiraterone with it three pronged action and it ability to inhibit tissue androgens has regenerated interest in neoadjuvant therapy for localized prostate cancer.

In one randomized open-label phase II study ${ }^{28}$ the role of neoadjuvant therapy with abiraterone acetate's in localized high-risk patients fit for prostatectomy was examined. 58 patients were randomly assigned in 1:1 ratio to AA $(1,000 \mathrm{mg} / \mathrm{d})$, LHRHa (intramuscular; total of $22.5 \mathrm{mg}$ over 12 weeks [7.5 $\mathrm{mg}$ every 4 weeks]) plus prednisone ( $5 \mathrm{mg} / \mathrm{d}$ ) versus LHRHa for 12 weeks. This was followed by a research prostate biopsy for tissue hormone analysis. All patients received 12 additional weeks of LHRHa plus AA followed by radical prostatectomy. After 12 weeks the reduction in primary endpoint $\{$ (prostate tumor androgen levels (DHT and DHEA) $\}$ at was more with the combination therapy compared to leuprolide alone $(P<0.0001)$. Administration of abiraterone acetate ( 6 month Vs 3 month) achieved a greater percentage of pathologic complete response (CR) $(10 \%$ vs. 
$4 \%$, respectively), near pathologic CR ( $24 \%$ vs. $11 \%$, respectively), and any disease shrinkage, as assessed by a composite endpoint of true pathologic CR plus near CR (15\% vs. $34 \%$, respectively). ${ }^{29-32}$

\section{Safety and tolerability}

Abiraterone, selectively inhibits the enzyme CYP17 (17 $\alpha$ - Hydroxylase and C17,20 -lyase). As a consequence of $17 \alpha$-Hydroxylase inhibition there is reduction of cortisol levels and compensatory overproduction of mineralocorticoids. After abiraterone therapy there is rise of deoxycorticosterone and corticosterone levels, resulting in secondary mineralocorticoid excess characterized by hypokalaemia, hypertension and fluid retention or oedema In clinical trials of Abiraterone adverse events were predominantly grade 1 or 2 (fatigue, joint swelling or discomfort, edema, hot flush, diarrhea, vomiting, cough, hypertension, dyspnea, urinary tract infection and contusion), with a low rate of drug discontinuation or dose reduction. Grade 3 and 4 adverse events occurred in less than $10 \%$ of patients.

\section{Conclusion}

Historically, the treatment of metastatic prostate cancer consisted of palliative treatment until the arrival of docetaxel, which showed improved overall survival. In recent years, several new agents have been approved for use in the post-docetaxel setting, with potential for use in a first line setting. One of these agents, abiraterone acetate, is an oral prodrug and when ingested it is converted to its active metabolite, abiraterone in liver. Both abiraterone and abiraterone acetate are selective irreversible inhibitors of CYP17. Abiraterone acetate in combination with prednisone has demonstrated overall survival benefit in men with metastatic CRPC who received previous docetaxel therapy and in men with no previous chemotherapy. The combination of abiraterone acetate and prednisone resulted in a significantly longer median progression free survival in both patient populations. Although there is much to understand regarding newer agents, including the appropriate sequence of use, abiraterone has been shown to be an appropriate option with overall survival benefit and tolerable side effect profile.

\section{Acknowledgments}

None.

\section{Conflicts of interest}

The author declares there is no conflict of interest.

\section{References}

1. Acar O, Esen T, Lack NA. New therapeutics to treat castrateresistant prostate cancer. Scientific World Journal. 2013;379641.

2. Semenas J, Allegrucci C, Boorjian SA, et al. Overcoming Drug Resistance and Treating Advanced Prostate Cancer. Curr Drug Targets. 2012;13(10):1308-1323.

3. Gee A, Challapalli A, Bahl A. Health-related quality of life in men with metastatic castration-resistant prostate cancer. Expert Rev Pharmacoecon Outcomes Res. 2015;15(6):941-949.

4. Tannock IF, de Wit R, Berry WR, et al. Docetaxel plus prednisone or mitoxantrone plus prednisone for advanced prostate cancer. $N$ Engl $J$ Med. 2004;351(15):1502-1512.

5. El-Amm J, Aragon-Ching JB. The changing landscape in the treatment of metastatic castration-resistant prostate cancer. Ther Adv Med Oncol. 2013;5(1):25-40.
6. Hurwitz M, Petrylak DP. Sequencing of agents for castration-resistant prostate cancer. Oncology (Williston Park). 2013;27(11):1144-1149.

7. Cookson MS, Roth BJ, Dahm P, et al. Castration-Resistant Prostate Cancer: AUA Guideline. J Urol. 2013;190(2):429-438.

8. Tadas S Vasaitis, Robert D Bruno, Vincent CO Njar. CYP17 inhibitors for prostate cancer therapy. J Steroid Biochem Mol Biol. 2011;125(12):23-31.

9. Janssen Biotech Inc. ZYTIGA_(abiraterone acetate) tablets: prescribing information. 2013.

10. de Bono JS, Logothetis CJ, Molina A, et al. Abiraterone and increased survival in metastatic prostate cancer. NEngl J Med. 201;;364(21):19952005 .

11. Fizazi K, Scher HI, Molina A, et al. Abiraterone acetate for treatment of metastatic castration-resistant prostate cancer: final overall survival analysis of the COU-AA-301 randomised, double-blind, placebocontrolled phase 3 study. Lancet Oncol. 2012;13(10):983-992.

12. Ryan CJ, Smith MR, de Bono JS, et al. Abiraterone in metastatic prostate cancer without previous chemotherapy. NEngl JMed. 2013;368(2):138148.

13. Ryan CJ, Smith MR, Fizazi K, et al. Abiraterone acetate plus prednisone versus placebo plus prednisone in chemotherapy-naive men with metastaticcastration-resistant prostate cancer (COU-AA-302): final overall survival analysis of a randomised, double-blind, placebocontrolled phase 3 study. Lancet Oncol. 2015;16(2):152-160.

14. Shameem R, Hamid MS, Xu KY, et al. Comparative analysis of the effectiveness of abiraterone before and after docetaxel in patients with metastatic castration-resistant prostate cancer. World $J$ Clin Oncol. 2015;6(4):64-72.

15. Broder MS, Gutierrez B, Cherepanov D, et al. Burden of skeletal-related events in prostate cancer: unmet need in pain improvement. Support Care Cancer. 2015;23(1):237-247.

16. Weinfurt KP, Li Y, Castel LD, et al. The significance of skeletal-related events for the health-related quality of life of patients with metastatic prostate cancer. Ann Oncol. 2015;16(4):579-584.

17. Logothetis CJ, Basch E, Molina A, et al. Effect of abiraterone acetate and prednisone compared with placebo and prednisone on pain control and skeletal-related events in patients with metastatic castrationresistant prostate cancer: exploratory analysis of data from the COUAA-301 randomised trial. Lancet Oncol. 2012;13(12):1210-1217.

18. Saad F, Shore N, Van Poppel H, et al. Impact of bone-targeted therapies in chemotherapy-naïve metastatic castration-resistant prostate cancer patients treated with Abiraterone Acetate: post hoc analysis of study COU-AA-302. Eur Urol. 2015;68(4):570-577.

19. Caffo O, De Giorgi U, Fratino L, et al. Safety and clinical outcomes of patients treated with abiraterone acetate after docetaxel: results of the Italian Named Patient Programme. BJU Int. 2014;115(5):764-771.

20. Attard G, Reid AH, Yap TA, et al. Phase I clinical trial of a selective inhibitor of CYP17, abiraterone acetate, confirms that castrationresistant prostate cancer commonly remains hormone driven. J Clin Oncol. 2004;26(28):4563-4571.

21. Ryan CJ, Smith MR, Fong L, et al. Phase I clinical trial of the CYP17 inhibitor abiraterone acetate demonstrating clinical activity in patients withcastration-resistant prostate cancer who received prior ketoconazole therapy. J Clin Oncol. 2010;28(9):1481-1488.

22. Chi KN, Spratlin J, Kollmannsberger C, et al. Food effects on abiraterone pharmacokinetics in healthy subjects and patients with metastatic castration-resistant prostate cancer. $J$ Clin Pharmacol. $2015 ; 55(12): 1406-1414$. 
23. Leibowitz-Amit R, Seah JA, Atenafu EG, et al. Abiraterone acetate in metastatic castration-resistant prostate cancer: a retrospective review of the Princess Margaret experience of (I) low dose abiraterone and (II) prior ketoconazole. Eur J Cancer. 2014;50(14):2399-2407.

24. Petrioli R, Francini E, Fiaschi AI, et al. Reduced Dose of Abiraterone Acetate with Concomitant Low-dose Prednisone in the Treatment of $\geq$ 85 Year-old Patients with Advanced Castrate-resistant Prostate Cancer. Anticancer Res. 2015;35(5):3097-3102.

25. Greenberg DC, Wright KA, Lophathanon A, et al. Changing presentation of prostate cancer in a UK population-10 year trends in prostate cancer risk profiles in the East of England. Br J Cancer. 2013;109(8):21152120

26. Pron G. Prostate-Specific Antigen (PSA)-Based Population Screening for Prostate Cancer: An Evidence-Based Analysis. Ont Health Technol Assess Ser. 2015;15(10):1-64.

27. Lou DY, Fong L. Neoadjuvant therapy for localized prostate cancer: Examining mechanism of action and efficacy within the tumor. Urol Oncol. 2016;34(4):182-192.
28. Taplin ME, Montgomery B, Logothetis CJ, et al. Intense androgendeprivation therapy with abiraterone acetate plus leuprolide acetate in patients with localized high-risk prostate cancer: results of a randomized phase II neoadjuvant study. J Clin Oncol. 2014;32(33):3705-3715.

29. de Bono JS, Oudard S, Ozguroglu M, et al. Prednisone plus cabazitaxel or mitoxantrone for metastatic castration-resistant prostate cancer progressing after docetaxel treatment: a randomised open-label trial. Lancet. 2010;376(9747):1147-1154.

30. Scher HI, Fizazi K, Saad F, et al. Increased survival with enzalutamide in prostate cancer after chemotherapy. NEnglJMed.2012;367(13):11871197.

31. Parker C, Nilsson S, Heinrich D, Helle SI, et al. Alpha emitter radium-223 and survival in metastatic prostate cancer. $N$ Engl $J$ Med. 2013;369(3):213-223.

32. Kantoff PW, Higano CS, Shore ND, et al. Sipuleucel-T immunotherapy for castration-resistant prostate cancer. $N$ Engl J Med. 2010;363(5):411-422. 